\title{
DNA Marker Based Diversity Across Rice Genotypes and Advanced Breeding Lines Bred for Temperate India
}

\section{Nakeeb un Nisa Yetoo}

SKUAST Kashmir: Sher-E-Kashmir University of Agricultural Sciences and Technology Kashmir https://orcid.org/0000-00021316-179X

\section{Aafreen Sakina}

SKUAST Kashmir: Sher-E-Kashmir University of Agricultural Sciences and Technology Kashmir

Najeebul Rehman* Sofi ( $\nabla$ najeeb_sofi@rediffmail.com )

Sher-E-Kashmir University of Agricultural Sciences and Technology Kashmir https://orcid.org/0000-0002-8934-3936

\section{Asif B. Shikari}

Sher-E-Kashmir University of Agricultural Sciences and Technology Kashmir

\section{Reyaz R. Mir}

Sher-E-Kashmir University of Agricultural Sciences and Technology Kashmir

\section{Ashraf Bhat}

Sher-E-Kashmir University of Agricultural Sciences and Technology Kashmir

\section{Showkat A. Waza}

Sher-E-Kashmir University of Agricultural Sciences and Technology Kashmir

\section{Sofora Jan}

Sher-E-Kashmir University of Agricultural Sciences and Technology Kashmir

\section{Sumira M.sc Rafiqee}

Sher-E-Kashmir University of Agricultural Sciences and Technology Kashmir

\section{Gazala H. Khan}

Sher-E-Kashmir University of Agricultural Sciences and Technology Kashmir

\section{Shabir H. Wani}

Sher-E-Kashmir University of Agricultural Sciences and Technology Kashmir

\section{Research Article}

Keywords: Rice, Genetic diversity, Molecular markers, SSRs, Indica, Japonica, Kashmir Himalayas

Posted Date: January 3rd, 2022

DOI: https://doi.org/10.21203/rs.3.rs-1148107/v1

License: (c) This work is licensed under a Creative Commons Attribution 4.0 International License. Read Full License 


\section{Abstract}

Background: Characterization and evaluation of plant genetic resources play an important role for their utilization in the crop improvement programmes.

Methods and results: This study entails the agro-morphological, cooking quality and molecular characterization of 51 genotypes / advance breeding lines of rice from Kashmir Himalayas. Significant variability was observed for all agromorphological and cooking quality traits among all the studied genotypes. Cluster analysis using UPGMA method divided the genotypes into two major clusters having 15 and 36 genotypes. Thirty eight genotypes screened using 24 SSR markers detected 48 alleles with 2.0 alleles per locus and an average polymorphism information content (PIC) of 0.37. High polymorphism information content (PIC) values was observed for the primers RM263 (0.67), RM159 (0.59) and RM333 (0.50). Furthermore, out of 38 SSR markers screened on 192 temperate rice germpalsm lines, R4M17 accurately differentiated indica and temperate japonica genotypes amplifying 220 bp and 169bp, respectively. Accordingly, 15 genotypes were reported as indica and 28 temperate japonica in addition to 149 genotypes as intermediate types.

Conclusion: The information on marker-based diversity and performance based on cooking quality and agronomic traits helped to select the most divergent lines for crossing and also the analysis was useful to generate information on indica - japonica classification of our germplasm.

\section{Introduction}

Rice (Oryza sativa L.) is a staple crop of Kashmir Himalayas and covers an area of 150 thousand hectares grown above $1550 \mathrm{msl}$. The cultivars grown include landraces and formally bred varieties which belong to cold tolerant indica and temperate japonica. Genetic improvement in any crop species is inexorable and a continuous process to meet the future challenges regarding food security. Evaluation, characterization and identification of plant genetic resources play an important role for their utilization in the crop improvement programmes [1, 2]. The landraces, traditional and improved cultivarstogetherrepresent repositories of genetic diversity and can serve as resources for improving yield and resistance to pests and diseases [3-5] or else can be used as parents in development of superior recombinants [6]. Conventionally, morphological traits have been used to determine the genetic diversity and for classification ofthe germplasm into different groups. Alternately, the genetic diversity can be estimatedthrough the use of molecular markers which offer a high polymorphism range and reproducibility $[7,8]$. The PCR based markers such asmicrosatellites or simple sequence repeats (SSRs) are highly polymorphic, reproducible, codominant and widely distributed throughout the rice genome [9]. The two of the sub species viz., indica and temeperate japonica are being grown across irrigated ecologies of Kashmir valleywith $80 \%$ and $20 \%$ of the total (1.4 lakh ha) rice grown area, respectively [10]. The present study was undertaken to generate an information on genetic divergence and sub-species allocation of a set of elite rice genotypes which are targeted for different mountainous ecological niches across Kashmir valley.

\section{Materials And Methods}

Evaluation for agronomic and quality related traits

Fifty one temperaterice accessions were grown under irrigated field conditionsat MRCFC, Sher-e-Kashmir University of Agricultural Sciences and Technology of Kashmir, Khudwani Campus ( $34^{\circ} \mathrm{N}$ latitude and $74^{\circ} \mathrm{E}$ longitude at $\left.1690 \mathrm{msl}\right) \mathrm{during}$ the Kharif season of 2018-19 (Table 1). Thematerialswere raised in a randomized complete block design with three replications. Thirty days old seedlings of each accession were transplanted in the fieldwith the standard spacing of $20 \mathrm{~cm} \times 15 \mathrm{~cm}$ and net plot size of $5 \mathrm{~m}^{2}$ perreplication. Recommended package of practices were followed to raise a healthy crop. Five randomlyselected plants from each replication were selected for recording the observations on various agromorphological traits. However, flowering, maturity and yield data was recorded on whole plot basis. The description of various agro-morphological traits along with grain quality features was carried outusing Standard Evaluation System of IRRI [11]. Amylose content and gel consistency were determined by the method developed by Juliano [12] and Cagampang [13], respectively. Alkali spreading value and Aroma were determined as per the procedure described by Jennings [14]. 
Similarly the list of germplasm lines (192 genotypes) for their classification into indica and temperate japonica groups are given in the Table 2.

\section{DNA Marker analysis}

The SSR markers used for the characterization of 38 varieties/advanced breeding lines were randomly selected from www.gramene.org. The selected microsatellite markers (two each for one chromosome) along with their chromosomal location and annealing temperature $(\mathrm{Tm})$ are presented in the Table 3. Genomic DNA was extracted following the CTAB (Cetyl-Tri Methyl Ammonium Bromide) method with some modifications [15]. Quantification of DNA samples was done spectrophotometrically and quality was estimated by using $0.8 \%$ agarose gel electrophoresis. High concentration of DNA samples was further diluted in 10:1 Tris-EDTA to a working concentration of $50 \mathrm{ng} / \mu \mathrm{l}$ and stored at $40 \mathrm{C}$ for PCR based marker analysis. PCR reaction was prepared with $50 \mathrm{ng}$ of rice genomic DNA, $0.2 \mu \mathrm{g}$ of $3 \dot{c}$ and $5 \dot{c}$ end primers, $200 \mathrm{mM}$ of each dNTP, 1 X PCR buffer containing 50 $\mathrm{mM} \mathrm{KCL}, 10 \mathrm{mM}$ Tris $\mathrm{HCl}\left(\mathrm{pH}\right.$ 8.9), $2.0 \mathrm{mM} \mathrm{MgCl}_{2}$ and one unit of Taq Polymerase in a total of $25 \mu \mathrm{L}$ solution individually for all 24 primer pairs. PCR thermal cycler was programmed for $1 \mathrm{~min}$ at $94^{\circ} \mathrm{C}, 1 \mathrm{~min}$ and 30 seconds at $55^{\circ} \mathrm{C}, 1 \mathrm{~min}$ at $72^{\circ} \mathrm{C}$ and a final cycle of $10 \mathrm{~min}$ at $72^{\circ} \mathrm{C}$. Amplification product was separated on $3.5 \%$ of agarose gel in $1 \mathrm{X}$ TBE buffer followed by staining with ethidium bromide. The SSR allele sizes were determined by the position of bands relative to the DNA ladder. Number 1 was given to the allele having highest molecular weight. The amplified bands were recorded as 1 (band present) and 0 (band absent) in a binary matrix.

\section{Statistical analysis}

The set of observations recorded for was subjected to statistical analysis. Analysis of variance was carried out for various agro-morphological traits as per Gomez and Gomez [16]. Analysis of molecular variance was performed using software GenAlEx version 6.5. Euclidian distance and Jaccards coefficients were calculated from morphological and marker data, respectively. Unweighted Pair Group Method using Arithmetic Averages (UPGMA) method was used to obtain the disimilarity trees from the two matrices, respectively, with the help of DARwin software (version 6.0.21). PIC values for each of the 24 primers were estimated using the equation proposed by Anderson [17]:

\section{$\mathrm{PIC}=\sum_{i=1}^{n}(\mathbf{p i j})^{2}$}

Where pij is the frequency of $\mathrm{j}^{\text {th }}$ allele in $\mathrm{i}^{\text {th }}$ primer and summation extends over ' $\mathrm{n}$ ' patterns.

Furthermore, the list of markers used in indica-temperate japonica differenriation is given in Table 4.

\section{Results}

The mean squares due to present set of genotypes were highly significant for all the characters studied (S.Table 1). ANOVA of some important agronomic and cooking quality traits are given in Table 5.Among the various quality features, amylose content and presence of aroma influence the consumer preferences and thus drive the breeding strategy. In the present study, amylose content ranged from $15.8 \%$ to $25.5 \%$ with minimum in Aromatic Zag and maximum in SKUA-420 (Fig. 1). Aromatic rices are highly demanded in the national and global markets. Among the rice varieties examined, SKUA-485, Mushk Budji, SKUA-494 and Pusa Sughandh 3 showed strong aroma. SKUA-420 and Aromatic Zag revealed the presence of mild aroma. Kamad, Nunbeoul, Shalimar Rice-4 and Koshihikari showed low aroma and the remaining 41 genotypes were completely non-aromatic (Fig. 2).

\section{Cluster analysis using morphological traits}

Cluster analysis was carried out to assess the extent of divergence using UPGMA method. The set of genotypes got grouped into two major clusters. Cluster I had 15 genotypes, and was further sub grouped into cluster la, Ib, Ic and Id with four, five, one 
and five genotypes, respectively. The remaining 36 genotypes marked the cluster II and were sub grouped into Ila, Ilb, Ilc and Ild with seven, eight, seven and 14, genotypes, respectively (Fig. 3).

\section{Molecular characterization}

PCR assay carried out on 38 genotypes using 24 SSR markers revealed three of them (RM1, RM60 and RM308) as monomorphic across all genotypes. A total of 48 alleles were amplified and the number of alleles per locus generated by each marker ranged from 1(RM60, RM130, RM159, RM236, RM308 and RM332) to 3 (RM1, RM105, RM204, RM216, RM224, RM226, RM295, RM335 and RM340) with an average number of 2.0 per locus (Table 3) (Fig. 4).

The polymorphism information content (PIC) value ranged from 0 to 0.665 with an average of 0.37 . High PIC values were observed for the primers RM263 (0.67), RM159 (0.59) and RM333 (0.50), while primers RM1, RM60 and RM308 (0) and RM105 (0.05) showed lower values of PIC (Table 3). PIC provides an estimate of discriminatory power of a marker by taking into account the relative frequency of the alleles. PIC values exceeding 0.5 reflects abetter polymorphism range [18]. Therefore, the markers RM 263, RM159 and RM333 can be effectively used for determining the genetic differences among the rice genotypes and to study their phylogenetic relationship.

The trend line of number of effective alleles $\left(\mathrm{N}_{\mathrm{e}}\right)$ versus expected heterozygosity $\left(\mathrm{H}_{\mathrm{e}}\right)$, was plotted and marked a maxiumum value of $\mathrm{N}_{e}=2.5$ that indicated the, high discriminatory power of the markers. Ideally the number of effective alleles should approximate to the number of actual alleles (Fig. 5).

\section{Cluster analysis and genetic divergence pattern}

The cluster analysis carried out through Unweighted Pair Group Method using Arithmetic Averages (UPGMA) helped to classify 38 genotypes into 2 clusters at an average dissimilarity of 30\%. Cluster I consisted of 24 genotypes and got further divided into two sub clusters; sub-cluster la consisted of 9 genotypesand sub cluster Ib of 15 genotypes. Similarly, cluster II contained 13 genotypes and is divided into two sub clusters viz; lla which consisted of 10 genotypes and llb with 3 genotypes (Fig. 6).

\section{Indica-japonica differentiation}

The 192 rice germpalsm lines got differentiate into indica and temperate japonica while using 38 SSR markers. Some of these markers included R1M30, R1M37, R1M47, R3M30, R4M17, R5M13, R5M20, R6M44, R7M7, R7M37, R9M10, R10M17, R10M30, R10M40 and R11M23 (Table 4). Out of these markers R4M17 accurately categorized indica and temperate japonica rice with $220 \mathrm{bp}$ and 169bp, respectively. Besides another marker R5M13 amplified 175bp in japonica and 207bp in indica. Another set of markers (S01022, S01160, S02057B, S02085, S03027, S03048, S03136, S03145, S04060, S04077B, S04087A, S04097B, S04129B, S07048, S07050A, S09000A, S09026B, S09040B, S09058, S09065, S09073, S10001 and S10003A) was validated across some known varieties such as Pusa Sugandh 3, Pusa Basmati 1509, SKUA-420, SKUA-495, K-332, Mushk Budji, Kamad, IR-64, K-39, IR-70, and Shalimar Rice-2. Of these, only S04077B and S09026B were found to clearly differentiate between indica and temperate japonica rice. For marker S04077B, 174bp allele was found to be associated with temperate japonica and $201 \mathrm{bp}$ with indica. The marker S09026B produced 207bp allele in japonica and $182 \mathrm{bp}$ allele in indica. Thereofore, out of 38 SSR markers only four SSR markers (R4M17, R5M13, S04077B and S09026B) perfectly categorized indica and temperate japonica rice. These four markers were further screened on 194 genotypes for the purpose of indica-japonica classification. Among the 192 genotypes 15 were indica and 28 temperate japonicas in addition to 149 varieties that belonged to intermediate type (Table 6). With respect to the fingerprint devised based on the four markers, genotypes which amplified 220, 182, 207 and $201 \mathrm{bp}$ fragments were regarded as indica while 169, 207,175, 174 bp as temperate japonica (S.Table 2). Any genotype with mixed combination of these alleles was categorized as intermediate type.

\section{Discussion}

Characterization of germplasm accessions establishes distinctiveness among rice genotypes. It is not only important for utilizing the appropriate attribute based donors in breeding programmes, but also essential in the present era for protecting the 
uniqueness of germplasm collections. In the present investigation 51 rice genotypes were evaluated for different agromorphological and physiochemical parameters and 38 genotypes were evaluated for molecular characterization. Further, 192 rice germplasm lines were used for indica-japonica differentiation. The mean sums of squares due to genotype were significant for all agro-morphological and quality traits. The high variability for plant height is in agreement with Chakravorty and Priyanka $[19,20]$. Significant variability for days to $50 \%$ flowering in the present study supports the findings of Sajid [21]. Similarly, significant variability for grain yield as observed in this study was supported by the findings of Vanisree and Tuhina-Khatun $[22,23]$. Nascimento [24] observed significant differences and high variability for flag leaf length, number of tillers per plant, panicle length, panicle fertility, 1000 grain weight which is similar to that in the present study. Similar results were reported by Sravan [25] for number of tillers, flag leaf length, plant height and panicle length. Richa [26] observed highly significant differences for the characters viz., plant height, tillers per plant, days to flowering, days to maturity, grain yield per plant, effective tillers per plant, grain length, grain breadth, length-breadth ratio and 1000 grain weight. Significant variability for days to $50 \%$ flowering, days to maturity, plant height, number of effective tillers per plant, panicle length, spikelet fertility percent, test weight, grain yield was reported by Kumari and Umesh [27-28]. Similarly, Waza and Jaiswal [29] reported significant variability for grain length, grain breadth, grain length/breadth ratio, 100 grain weight, kernel length, kernel breadth, kernel length/breadth ratio, kernel length after cooking, kernel elongation ratio, alkali spreading value, amylose content and aroma. These findings are in conformation with the results of present study.

Pusa Sugandh 3 revealed 25.3\% amylose content, which is similar to the previous reports by Bano and Majid [30, 31]. Rice with low amylose content (10-20\%) tends to be sticky and soft on cooking and becomes firmer as amylose content increases. Rice with intermediate amylose content (20-24\%) cooks moist and remains soft on cooling. High amylose content ( $\nabla 25 \%)$ rice is known to cook dry and fluffy, and becomes hard on cooling [32]. Rice with intermediate amylose is usually preferred in Inian Sub-continent. In general, the germplasm with medium amylose content coupled with other desirable quality traits can be the ideal source for use in rice breeding programs. Similarly, presence of aroma is another important trait in rice. Sensory evaluation of rice grain aroma revealed the range of sensory scores between 0 and 3. Pachauri [33] reported the similar results.

In the present study, based on morpgological diversity analysis, the set of genotypes were grouped into two major clusters (Fig. 3). Similar results were also reported by Madhubabu and Sruthi [34, 35].

In the present investigation, the level of polymorphism among the genotypes of rice was evaluated from the number of alleles and PIC value for each of the 24 SSR loci. Each of loci differed significantly in their ability to determine variability among the genotypes. A total of 48 alleles were amplified and the number of alleles per locus generated by each marker ranged from 1 to 3 with an average number of 2.0 per locus (Table 3). The polymorphism information content (PIC) value ranged from 0 to 0.665 with an average of 0.37 . McCouch [36] observed an average value of 2.08 alleles per locus among 48 traditional indigenous aromatic genotypes of rice using SSR markers. SSR markers are considered to be most amenable for genetic divergence studies due to their multiallelic nature, high reproducibility, co-dominant inheritance, extensive genomic coverage [37], exhibition of high degree of allelic variation [38] and ability to detect genetic variation within and between the accessions [39]. Saba [40] in their study observed the PIC value raging from 0.25 (RM3872) to 0.98 (RM321) with an average value of 0.63.

In the molecular analysis, the 38 genotypes got grouped into 2 clusters (Fig. 6). Clustering of genotypes based on marker data has been reported in earlier studies too. Rashmi [41] grouped 65 genotypes into 9 clusters by UPGMA mean clustering method. Similarly, Richa [26] grouped the genotypes into 4 major clusters based on UPGMA clustering method with Jaccard's similarity coefficient ranging from 0.38 to 0.92. Maliha, Exonam and Prasad [42-44] also reported the similar results.

Genetic diversity and differentiation in indica and japonica groups of the 192 rice germplasm was studied by assaying 38 markers (InDel and STS) that clustered them into 15 indica and 28 temperate japonicas in addition to 149 varieties that belonged to intermediate type (Table 6). The studies on Indica-japonica differentiation was previously carried out by Yong, Bao and Zhiyuan [45-47].

\section{Conclusions}


The genotypes which preserve the significant amount of genetic variability for the important agro-morphological traitswere broadly grouped into two clusters. The information on marker-based diversity and performance based on cooking quality and agronomic traitscan help with regard to the effective utilization of the germplasm. Further, the indica-japonica classification of the germplasm lines shall be helpful to devise a strategy for inter-sub species hybridization to breed for improved indicalinous and japanicalinous types that can fit in temperate climatic conditions.

\section{Declarations}

Acknowledgments The authors acknowledge the Sher-e-Kashmir University of Agricultural Sciences and Technology of Kashmir, (SKUAST-K) Wadura Agriculture college and Mountain Research Centre for Field Crops (MRCFC) Khudwani Anantnag for letting us work in their labs and providing matrial for the study.

Funding No funds/grants was received for conducting this study.

Competing interests All the authors declare no relevant financial or non-financial interests.

\section{Authors contribution}

Najeebul R. Sofi and Asif Bashir Shikari conceived the experiment. Nakeeb-Un-Nisa, Sofora Jan, Reyaz R. Mir and Najeebul R. Sofi conducted the DNA marker analysis for estimation of genetic diversity. Aafreen Sakina, Gazala H. Khan and Asif Bashir Shikari carried molecular marker work on indica-japonica differentiation. Materials were maintained by Najeebul R. Sofi and morphological data was generated by Nakeeb-Un-Nisa, Sumira Rafiqee and Shabir H. Wani. Analysis was carried out by Nakeeb-Un-Nisa, Asif Bashir Shikari, Reyaz R. Mir and Showkat A. Waza.

Ethical approval Not applicable

Consent to participate Not applicable

Consent to publish All the authors have read and agreed to published version of the manuscript

\section{References}

1. Lin MS (1991) Genetic base of japonica rice varieties released in Taiwan. Euphytica 56:43-46

2. Laxuman C, Salimath P, Varma M (2011) Molecular mapping and tagging of quantitative trait loci in rice-molecular breeding in rice. Lambert Academic Publishing GmbH \& Co, Germany

3. Mandel JR, Dechaine JM, Marek LF, Burke JM (2011) Genetic diversity and population structure in cultivated sunflower and a comparison to its wild progenitor, Helianthus annuus L. Theor Appl Genet 123:693-704

4. Vung O, Lal CY, Rai PHC (2012) Studies on genetic diversity in rice (Oryza sativa L.). Journal of AgriculturalTechnology 8:1059-1065

5. Bidhan R (2013) Genetic diversity in farmers' varieties and some advance lines of aromatic rice (Oryza sativa L.) from West Banga. Indian Journal of Plant Genetic Resources 26(3):215-219

6. Nayak AR, Chaudhury D, Reddy JN (2004) Genetic divergence in scented rice. Oryza 41:79-82

7. Waza SA, Rastogi NK, Verulkar SB, Bano D (2013) Fingerprinting and purity testing of rice hybrids using microsatellite markers. Indian Journal of Genetics and Plant Breeding 73(4):443-445

8. Shikari AB, Najeeb S, Khan G, Mohiddin FA, Shah AH, Nehvi FA, Wani SA, Bhat NA, Waza SA, Subba Rao LV, Steele KA, Witcombe JR (2021) KASP ${ }^{\mathrm{TM}}$ based markers reveal a population sub-structure in temperate rice (Oryza sativa L.) germplasm and local landraces grown in the Kashmir valley, north-western Himalayas. Genet Resour Crop Evol 68:821834

9. Chen X, Cho YG, Mc-Couch SR (2002) Sequence divergence of rice microsatellites in Oryza and other plant species. Mol Genet Genomics 268:331-343 
10. Najeeb R, Sofi, Ashaq H, Shikari AB, Sofi MD, Teli NA, Mohiddin FA, Bhat NA (2020) Rice crop in Kashmir valley: historical perspective, challenges and oppurtinities for sustainable production and livelihood improvement. SKUAST Journal of Research 22(1):1-18

11. IRRI (International Rice Research Institute) (2015) Standard Evaluation System for rice (SES), 6th edition. Los Banos (Phillipines): International Rice Research Institute

12. Juliano BO (1971) A simplified assay of milled rice amylase. Cereal Science Today 16(10):334-339

13. Cagampang GB, Perez CM, Juliano BO (1973) A gel consistency test for eating quality of rice. J Sci Food Agric 24(12):1589-1594

14. Jennings PR, Coffman WR, Kauffman HE (1979) Grain quality in rice improvement. International Rice Research Institute, Los Banos, Philippines 6: 113-118

15. Doyle JJ, Doyle JL (1990) Isolation of plant DNA from fresh tissue. Bioacoustics Research Laboratory Focus 12:13-15

16. Gomez KA, Gomez AA (1984) Staitstical procedures for agricultural research, 2 edn. John Wiley and sons, New York, $p 680$

17. Anderson JA, Churchill GA, Autrique JE, Tanksley SD, Sorrells ME (1993) Optimization parental selection for genetic linkage maps, vol 36. Genome, pp 181-188

18. Dewoody JA, Honeycutt RL, Skow LC (1995) Microsatellite marker in white-tailed deer. J Hered 86:317-319

19. Chakravorty A, Ghosh PD, Sahu PK (2013) Multivariate analysis of lanraces of rice of West Bengal. American Journal of Experimental Agriculture 3(1):110-123

20. Priyanka K, Jaiswal HK, Waza SA, Sravan T (2015) Genetic divergence in indigenous aromatic rice (Oryza sativa L.). Electronic Journal of Plant Breeding 6(4):1096-1102

21. Sajid M, Shahid AK, Haris K, Javed I, Ali MNS, Syed MAS (2015) Characterization of rice (Oryza sativa L.) germplasm through various agro-morphological traits. Science Agriculture 9(2):83-88

22. Vanisree S, Reddy PN, Surender RC, Reddy BG, Jagadeeswar R, Verma RG, Suryanarayana Y, Krishna L, Reddy PR (2011) Sugandha Samba (RNR2465), first-ever high-yielding, aromatic, short-grained rice variety of Andhra Pradesh, India. Genetic Resource36: 117-222

23. Tuhina-Khatun, Hanafi MM, Yusop MR, Wong MY, Salleh FM, Ferdous J (2015) Genetic variation, heritability and diversity analysis of upland rice (Oryza sativa L.) genotypes based on quantitative traits.BioMed Research Internationalpp.1-7

24. Nascimento WF, Silva EF, Veasey EA (2011) Agro-morphological characterization of upland rice accessions.Scientia Agricola (Piracicaba, Braz.). 68:652-660

25. Sravan T, Jaiswal HK, Waza SA, Priyanka K (2016) Analysis of variability and character association in indigenous aromatic rice (Oryzasativa L.). Electronic Journal of Plant Breeding pp.159-164

26. Richa S, Salgotra RK, Bhat JA (2017) Comparative diversity analysis in advanced breeding lines of basmati rice (Oryza sativa L.) using agro-morphological and SSR markers. Research Journal of Biotechnology 12(4):85-93

27. Sanju K, Singh PK, Bisen P, Bapsila L, Rai VP, Sinha B (2018) Genetic diversity analysis of rice (Oryza sativa L.) germplasm through morphological markers. International Journal of Agriculture, Environment and Biotechnology, pp 953-957

28. Umesh, Jaiswal HK, Sravan T, Waza SA, Bhardwaj R (2015) Estimation of genetic variability, heritability and genetic advance for yield and quality traits in some indigenous basmati rice (Oryza sativa L.) genotypes. International Journal of Farm Science 5:32-40

29. Waza SA, Jaiswal HK (2015) Effects of WA cytoplasm on various quality characteristics of rice hybrids. Journal of Animal and Plant Science 25:1693-1698

30. Bano DA, Singh SP, Waza SA (2017) Generation mean analysis for yield and quality traits in aromatic genotypes of rice (Oryza sativa L.). International Journal of Pure and Applied Biosciences 5(6):70-878

31. Majid A, Parray GA, Sofi NR, Shikari AB, Waza SA, Maqbool S, Khan MA, Sheikh FA (2019) Evaluation of grain quality traits in high altitude rice hybrids (Oryza sativa L.). Indian Journal of Pure and Applied Biosciences 7(5):525-530

32. Adu-Kwarteng E, Ellis WO, Oduro I, Manful JT (2003) Rice grain quality: A comparison of local varieties with new varieties under study in Gana. Food Contro I14:507-514 
33. Pachauri V, Nilay T, Vikram P, Singh NK, Singh S (2013) Molecular and morphological characterization of Indian farmer rice varieties. Aust J Crop Sci 7(7):923-932

34. Madhubabu P, Surendra R, Suman K, Chiranjeevi M, Abdul Fayaz R, Sanjaava Rao D, Chaitanya U, Subba Rao LV, Ravindra Babu V, Neeraja CN (2020) Assesment of genetic varability for micronutrient contentand agromorpological traits in rice (Oryza sativa L.). Indian Journal of Genetics 80(2):130-139

35. Sruthi K, Divya B, Senguttuvel P, Revathi P, Kemparaju KB, Koteswararao P, Sundaram RM, Vikram Jeet S, Rangith Kumar E, Bhowimick Kumar P, Vinod KK, Gopala Krishnan S, Singh AK, Hari Prasad AS (2019) Evaluation of genetic diversity of parental lines for development of heterotic groups in hybrid rice (Oryza sativa L.). J Plant Biochem Biotechnol 29:236-252

36. Meti N, Samal KC, Bastia DN, Rout GR (2013) Genetic diversity analysis in aromatic rice genotypes using microsatellite based simple sequence repeats (SSR) marker. Afr J Biotechnol 12:4238-4250

37. McCouch SR, Kochert G, Yu ZH, Wang ZY, Khush GS, Coffman WR, Tanksley SD (1998) Molecular mapping of rice chromosomes. Theor Appl Genet 76:815-829

38. Temnykh S, Park WD, Ayres N, Cartinhour S, Hauck N, Lipovich L, Cho Ishii T, McCouch SR (2000) Mapping and genome organization of microsatwllite sequence in rice (Oryza sativa L). Theor Appl Genet 100:6907-6712

39. Gilbert JE, Lewis RV, Wilkinson MJ, Caligeri PDS (1999) Developing and appropriate strategy to assesss genetic variability in plant germplasm collections. Theortical and Applied Genetic spp.112-1131

40. Saba JA, Rafii MY, Latif MA, Siti ZS, Ibrahim WA, Gous M (2018) Genetic diversity of aromatic rice germplasm revealed by SSR markers.BioMed Research Internationalpp.1-12

41. Rashmi D, Prashant B, Shoumik S, Bapsila L, Sakshi S, Pallavi, Singh PK (2017) Genetic diversity analysis in rice (Oryza sativa L.) accessions using SSR markers. International Journal of Agriculture, Environment and Biotechnology 10(4):457467

42. Maliha A, Balram M, Durgarani VCh, Chandramohan Y, Ramesh T (2020) Assesment of genetic diversity of aerobic rice germplasm using SSR markers. Journal of Pharmacognosy and Phytochemistry 9(4):1122-1128

43. Exonam A, Andrew E, Malachy A, Afeez S, Fiot T (2020) Genetic diversity of Korean rice (Oryza sativa L.) germplasm for yield related traits for adoption in rice farming sysem in Nigeria. International Journal of Genetics and Genomics 8(1):1928

44. Prasad GSV, Padmavathi G, Suneetha K, Madhav MS, Muralidharan K (2020) Assessment of diversity of Indian aromatic rice germplasm collections for morphological, agronomical, quality traits and molecular characters to identify a core set for crop improvement. CABI Agriculture and Bioscience 1:13

45. Qi Y, Dongling hongliangZ, Meixing Z, Junli W, Li S, Fenghua D, Zichao W L (2009) Assesing indica-japonica differentiation of improved rice varieties using microsatellite markers. Journal of Genetics and Genomics 36(5):305-312

46. Bao-Rong L, Xingxing C, Xin J (2009) Efficient indica and japonica rice identification based on InDel molecular method: its implications in rice breeding and evolutionary research. Progress in Natural Science 19 (10):1241-1252

47. Zhiyuan X, Shujie Z, Yunyue W, Brian V, Ford-Lloyd, Min T, Xin J, Yue W, Huanxin Y, Xiao Y, Ping L, Bao-Rong L (2010) Differentiation and distribution of indica and japonica rice varieties along the altitude gradients in Yunnan Province of China as revealed by InDel. molecular markers GeneticResource and Crop Evolution 57:891-902.

\section{Tables}

Table 1 Experimental material used in agro-morphological and quality characterization

China-1007 , China-1039 , Chenab ${ }^{\natural}$, Jhelum, Shalimar Rice-1, Shalimar Rice-2 $2^{\natural}$, Shalimar Rice-3, Shalimar Rice-4 , SKUA-292, SKUA-

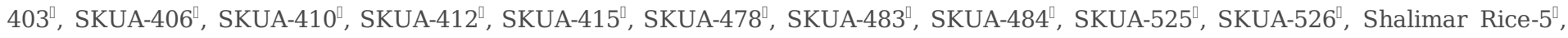

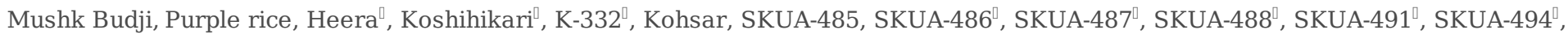




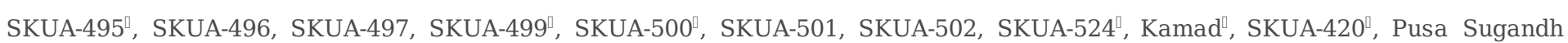
3 , SKUA-514 , SKUA-505 , Nunbeoul , Tangdar Zag , Aromatic Zag , SKUA-521, SKUA-522 , SKUA-523

${ }^{\square}$ Genotypes used in molecular analysis

Table 2 Experimental material used for classification into indica and temperate japonica

GS-88, GS-152, GS-183, GS-184, GS-189, GS-7, GS-22, GS-33, GS-34, GS-35, GS-36, GS-37, GS-59, GS-61, GS-63, GS-81, GS-103, GS106, GS-112, GS-116, GS118, GS-125, GS-126, GS-128, GS-129, GS-130, GS-133, GS-135, GS-139, GS-142, GS-145, GS-147, GS-155, GS161, GS-163, GS-164, GS-166, GS-177, GS-181, GS-188, GS-195, GS-199, GS-205, GS-208, GS-214, GS-231, GS-234, GS-237, GS-245, GS-246, GS-248, GS-255, GS-258, GS-263, GS-269, GS-272, GS-275, GS-276, GS-282, GS-290, GS-291, GS-305, GS-306, GS-318, GS-321, GS-322, GS-324, GS-326, GS-331, GS-332, GS-337, GS-344, GS-350, GS-351, GS-358, GS-363, GS-367, GS-368, GS-370, GS-372, GS-376, GS-381, GS-404, GS-410, GS-421, GS-435, GS-436, GS-434, GS-443, GS-444, GS-446, GS-450, GS-453, GS-461, GS-464, GS-467, GS468, GS-471, GS-474, GS-476, GS-477, GS-481, GS-487, GS-492, GS-499, GS-503, GS-504, GS-514, GS-518, GS-520, GS-531, GS-537, GS-539, GS-542, GS-543, GS-554, GS-574, GS-580, GS-581, GS-584, GS-585, GS-590, GS-592, GS-595, GS-597, GS-596, GS-598, GS-601, GS-602, GS-603, GS-617, GS-628, GS-634, GS-639, GS-662, SKUA-412, AVT-V2, AVT-FG-V5, AVT-IV1, SKUA-478, SKUA-496, Purple rice, AVT-FG-V10, AVT-FG-V2, , AVT-FG-V4, SKUA-404, AVT-FG-V7, SKUA-500, Egyptian rice, SKUA-415, SKUA-499, SKUA-491, AVTIV3, GS-203, GS-206, GS-307, GS-336, GS-337, GS-338, GS-340, GS-342, GS-416, GS-432, GS-455, GS-484, GS-490, GS-497, GS-530, GS-582, GS-583, GS-587, GS-588, GS-623, GS-624, Koshihikari, K-332GS-157, GS-162,GS-182, GS-185, GS-273, GS-373, GS-541, GS572, SKUA-339, SKUA-406, AVT-FG-V6,SKUA-483, Shalimar Rice-2,China-1007, Chenab, China-988,

Table 3 List of microsatellite markers along with their primer sequence and annealing temperature, number of alleles and PIC value

\begin{tabular}{|c|c|c|c|c|c|c|c|}
\hline $\begin{array}{l}\text { S. } \\
\text { No }\end{array}$ & $\begin{array}{c}\text { Marker } \\
\text { ID }\end{array}$ & $\begin{array}{c}\text { Chr. } \\
\text { Location }\end{array}$ & $\begin{array}{l}\text { Annealing } \\
\text { temperature }\end{array}$ & Forward Primer (5' to $3^{\prime}$ ) & Reverse Primer (5' to $3^{\prime}$ ) & $\begin{array}{l}\text { No. of } \\
\text { alleles }\end{array}$ & PIC \\
\hline 1. & RM1 & 1 & 54 & GCGAAAACACAATGCAAAAA & GCGTTGGTTGGACCTGAC & 1 & 0.00 \\
\hline 2. & RM60 & 3 & 55 & AGTCCCATGTTCCACTTCCG & ATGGCTACTGCCTGTACTAC & 1 & 0.00 \\
\hline 3. & RM72 & 8 & 53 & CCGGCGATAAAACAATGAG & GCATCGGTCCTAACTAAGGG & 2 & 0.45 \\
\hline 4. & RM105 & 9 & 65 & GTCGTCGACCCATCGGAGCCAC & TGGTCGAGGTGGGGATCGGGTC & 3 & 0.05 \\
\hline 5. & RM117 & 12 & 63 & CGATCCATTCCTGCTGCTCGCG & CGCCCCCATGCATGAGAAGACG & 2 & 0.48 \\
\hline 6. & RM130 & 3 & 62 & TGTTGCTTGCCCTCACGCGAAG & GGTCGCGTGCTTGGTTTGGTTC & 1 & 0.50 \\
\hline 7. & RM159 & 5 & 63 & GGGGCACTGGCAAGGGTGAAGG & GCTTGTGCTTCTCTCTCTCTCTCTCTCTC & 1 & 0.59 \\
\hline 8. & RM173 & 5 & 64 & TCGCGCTTCTTCCTCGTCGACG & CCCGCTTGCAGAGGAAGCAGCC & 2 & 0.48 \\
\hline 9. & RM204 & 6 & 56 & GTGACTGACTTGGTCATAGGG & GCTAGCCATGCTCTCGTACC & 2 & 0.45 \\
\hline 10. & RM216 & 10 & 54 & GCATGGCCGATGGTAAAG & TGTATAAAACCACACGGCCA & 3 & 0.43 \\
\hline 11. & RM224 & 11 & 54 & ATCGATCGATCTTCACGAGG & TGCTATAAAAGGCATTCGGG & 3 & 0.39 \\
\hline 12. & RM226 & 1 & 58 & AGCTAAGGTCTGGGAGAAACC & AAGTAGGATGGGGCACAAGCTC & 3 & 0.43 \\
\hline 13. & RM235 & 12 & 56 & AGAAGCTAGGGCTAACGAAC & TCACCTGGTCAGCCTCTTTC & 2 & 0.48 \\
\hline 14. & RM236 & 2 & 55 & GCGCTGGTGGAAAATGAG & GGCATCCCTCTTTGATTCCT & 1 & 0.30 \\
\hline 15. & RM242 & 9 & 55 & GGCCAACGTGTGTATGTCTC & TATATGCCAAGACGGATGGG & 2 & 0.27 \\
\hline 16. & RM248 & 7 & 55 & TCCTTGTGAAATCTGGTCCC & GTAGCCTAGCATGGTGCATG & 2 & 0.45 \\
\hline 17. & RM252 & 4 & 55 & TTCGCTGACGTGATAGGTTG & ATGACTTGATCCCGAGAACG & 2 & 0.30 \\
\hline 18. & RM263 & 2 & 57 & CCCAGGCTAGCTCATGAACC & GCTACGTTTGAGCTACCACG & 2 & 0.67 \\
\hline 19. & RM295 & 7 & 56 & CGAGACGAGCATCGGATAAG & GATCTGGTGGAGGGGAGG & 3 & 0.30 \\
\hline 20. & RM308 & 8 & 56 & GGCTGCACACGCACACTATA & TTACGCATATGGTGAGTAGGC & 1 & 0.00 \\
\hline 21. & RM332 & 11 & 56 & GCGAAGGCGAAGGTGAAG & CATGAGTGATCTCACTCACCC & 1 & 0.50 \\
\hline 22. & RM333 & 10 & 56 & GTACGACTACGAGTGTCACCAA & GTCTTCGCGATCACTCGC & 2 & 0.50 \\
\hline 23. & RM335 & 4 & 55 & GTACACACCCACATCGAGAAG & GCTCTATGCGAGTATCCATGG & 3 & 0.48 \\
\hline 24. & RM340 & 6 & 54 & GGTAAATGGACAATCCTATGGC & GACAAATATAAGGGCAGTGTGC & 3 & 0.50 \\
\hline
\end{tabular}

Table 4 Markers used in indica-japonica differentiation 


\begin{tabular}{|c|c|c|c|c|}
\hline S.No & Primer & Chromosome & Forward primer ( $5 \phi$ to $3 \phi)$ & Reverse primer (5\$ to $3 \phi)$ \\
\hline 1. & R1M30 & 1 & AAGGGGCCCTAATTTATCTAG & TGTTTACTTTGTTCTTGGACTG \\
\hline 2. & R1M37 & 1 & ATAGTTCGCCATCGTCAT & ACACGCCATAGCAAGGAA \\
\hline 3. & R1M47 & 1 & AATAGAATTACTGATGAAACCTTA & GCCCGTTACCGCTTATGT \\
\hline 4. & R3M30 & 3 & AGGCTAAGTGAAGAAATAATAAG & CTCCGTATTCATTACTGGTTG \\
\hline 5. & R4M17 & 4 & AGTGCTCGGTTTTGTTTTC & GTCAGATATAATTGATGGATGTA \\
\hline 6. & R5M13 & 5 & GAGAAAGAGTGGAAGGAG & AGTATCGTCAGGAGGGTC \\
\hline 7. & R5M20 & 5 & CTCGCTGTTTACTGACTGG & TTTGATGTACTGCCTGCTCT \\
\hline 8. & R6M44 & 6 & TTAGGAATAAAGGCTGGATA & TTACCGTTAATAGGTGGAA \\
\hline 9. & R7M7 & 7 & ACСТTСССТССССТTTTGAT & AACTTGGTCTTCCTGTTTTATTG \\
\hline 10. & R7M37 & 7 & CAGCCCTAAATCTAAATACCC & ACGTTGAGACAGGCGAGC \\
\hline 11. & R9M10 & 9 & CTTTGGATTCAGGGGGA & AACTTGAAACGGAGGCAG \\
\hline 12. & R10M17 & 10 & TGAACAATAAACCACAGAAGCA & СССТTТАТТСССТССТТТG \\
\hline 13. & R10M30 & 10 & CCCTAAAAATAGAGCAACCT & ACCCATAATACTACCAATCAAC \\
\hline 14. & R10M40 & 10 & GTCCCTAGGCCATCTCTTG & GCGAATAGGGGTGGACAG \\
\hline 15. & R11M23 & 11 & AAGGTTGACAAGGACAGAAG & TCGCAGGAATGGATAAAA \\
\hline 16. & S01022 & 1 & CATGGATGATGCTTCCCTCT & TTGACAGTGGCTCCACAAAG \\
\hline 17. & S01160 & 1 & TTGCGATTTATTTGCCAGTG & CCAGGCATCCAATGCTTATT \\
\hline 18. & S02057B & 2 & AGCСТCTTCTCССТССТСАС & TGCAAACACCATAACAACCAA \\
\hline 19. & S02085 & 2 & GCGAGAGTGTACCCCTTTGA & TGTGTACCTTGCACCCTGAA \\
\hline 20. & S03027 & 2 & TGAACATTTTGGTCGTCTGG & TTGACGAAGTCACCATAGACG \\
\hline 21. & S03048 & 3 & GGGATGGGAGAAGGGAATAA & GCCAGCTAGGATGTTGAAGG \\
\hline 22. & S03136 & 3 & GCATTAAGGCACACAAAGCA & TGTTTGTAATCCGCATGGAA \\
\hline 23. & S03145 & 3 & TCACCTACAGGAAGCAGCAG & GCCGTCGTTGAAGAAGTAGC \\
\hline 24. & S04060 & 3 & TATGGTTTTATCCGCCAACC & GCTACAACTAAAACAAGAAACGTGA \\
\hline 25. & S04077B & 4 & TCCCAGGTGAACTACGGACT & CAGCATTTTCAGTGGAAGCA \\
\hline 26. & S04087A & 4 & ATGTTTGGCAATCCGCTAAG & AAAGATGGTTGAGCGGAAGA \\
\hline 27. & S04097B & 4 & TCCACAGTCTGTCCGTGAAA & CTCCTTGTGCTGCAGAATTG \\
\hline 28. & S04129B & 4 & AATCGATTCATTCGCACAAA & CTTTCATGCTCTGCCATTGA \\
\hline 29. & S07048 & 6 & CATGGCACCTTGAGAGTTGA & ACACATGGAGCTGGCTTCTC \\
\hline 30. & S07050A & 7 & CTCCACTTATGGCAGCGAAT & CAAGTGAAGTGGGAGCAGGT \\
\hline 31. & S09000A & 8 & CCAATTCACGGTTTAACAAGG & GCCATGAAGCTTCGTTAGGA \\
\hline 32. & S09026B & 8 & GGGAGGCAGAGGGAACTACT & TTATCAGGCCAGGTCCTTTG \\
\hline 33. & S09040B & 8 & TAATATCGCATGGCAAGACG & ACTTTGCAGAGGCGACAAAC \\
\hline 34. & S09058 & 8 & CGTGAGAAGTCCAGTCCACA & ATTGATCGATTGGGGGATTT \\
\hline 35. & S09065 & 9 & TGTGTTCGACGTTTGACCAT & GGGCCAGGGTACATTGAATA \\
\hline 36. & S09073 & 9 & ACCACCCTGAACCACAACAT & TCACTGGGTTCTGTGTCCAA \\
\hline
\end{tabular}




\begin{tabular}{|c|l|l|l|l|} 
37. & S10001 & 9 & ATCGTGGTCGGGATTATGAG & GCATCATGGCTTTTGTGTTG \\
\hline 38. & S10003A & 9 & ATAAGACGGACGGTCAAACG & ATCTCTTGTGGGCTTTGTGG \\
\hline
\end{tabular}

Table 5 ANOVA of important agronomic and cooking quality traits

\begin{tabular}{|c|c|c|c|c|c|c|c|c|c|}
\hline \multicolumn{10}{|c|}{ Mean Squares } \\
\hline $\begin{array}{l}\text { Source of } \\
\text { variation }\end{array}$ & d.f & $\overline{\mathrm{DF}}$ & GY q/ha & $\begin{array}{l}\text { KLBC } \\
(\mathrm{mm})\end{array}$ & $\begin{array}{l}\text { L/B ratio } \\
\mathrm{BC}\end{array}$ & $\mathrm{KLAC}(\mathrm{mm})$ & $\mathrm{L} / \mathrm{B}$ ratio $\mathrm{AC}$ & KER & ASV \\
\hline Replication & 2 & 3.0653 & $104.4675 * *$ & 0.0224 & 0.0010 & 0.0628 & 0.0005 & 0.0010 & 0.4567 \\
\hline Treatments & 50 & $130.2732^{* *}$ & $1518.4569 * *$ & $1.4691^{* *}$ & $1.0833^{* *}$ & $4.3403^{* *}$ & $2.2071^{* *}$ & $0.0328 * *$ & $3.7513^{* *}$ \\
\hline Error & 100 & 3.2053 & 16.3088 & 0.0080 & 0.0009 & 0.0106 & 0.0009 & 0.0008 & 0.4474 \\
\hline
\end{tabular}

«* significant at $0.01 \%$ level of significance

<* $\mathrm{P}<0.01$

Table 6 Classification of germplasm based on the markers differentiating indica and japonica

\begin{tabular}{|c|c|c|}
\hline Indica & Japonica & Intermediate \\
\hline $\begin{array}{l}\text { GS-157, } \\
\text { GS-162, } \\
\text { GS-182, } \\
\text { GS-185, } \\
\text { GS-273, } \\
\text { GS-337, } \\
\text { GS-373, } \\
\text { GS-541, } \\
\text { GS-572, } \\
\text { SKUA- } \\
\text { 339, } \\
\text { SKUA- } \\
\text { 406, AVT- } \\
\text { FG-V6 } \\
\text {,SKUA- } \\
\text { 483, } \\
\text { Shalimar } \\
\text { Rice- } \\
\text { 2,China- } \\
\text { 1007, }\end{array}$ & $\begin{array}{l}\text { GS-88, GS-152, } \\
\text { GS-183, GS-184, } \\
\text { GS-189, GS- } \\
\text { 203, GS-206, GS- } \\
\text { 307, GS-336, GS- } \\
\text { 337, GS-338, GS- } \\
\text { 340, GS-342, GS- } \\
\text { 416, GS-432, GS- } \\
\text { 455, GS-484, GS- } \\
\text { 490, GS-497, GS- } \\
\text { 530, GS-582, GS- } \\
\text { 583, GS-587, GS- } \\
\text { 588, GS-623, GS- } \\
624, \\
\text { Koshihikari, K- } \\
332\end{array}$ & $\begin{array}{l}\text { GS-7, GS-22, GS-33, GS-34, GS-35, GS-36, GS-37, GS-59, GS-61, GS-63, GS-81, GS-103, GS-106, GS-112, } \\
\text { GS-116, GS118, GS-125, GS-126, GS-128, GS-129, GS-130, GS-133, GS-135, GS-139, GS-142, GS-145, } \\
\text { GS-147, GS-155, GS-161, GS-163, GS-164, GS-166, GS-177, GS-181, GS-188, GS-195, GS-199, GS-205, } \\
\text { GS-208, GS-214, GS-231, GS-234, GS-237, GS-245, GS-246, GS-248, GS-255, GS-258, GS-263, GS-269, } \\
\text { GS-272, GS-275, GS-276, GS-282, GS-290, GS-291, GS-305, GS-306, GS-318, GS-321, GS-322, GS-324, } \\
\text { GS-326, GS-331, GS-332, GS-344, GS-350, GS-351, GS-358, GS-363, GS-367, GS-368, GS-370, GS-372, } \\
\text { GS-376, GS-381, GS-404, GS-410, GS-421, GS-434, GS-435, GS-436, GS-443, GS-444, GS-446, GS-450, } \\
\text { GS-453, GS-461, GS-464, GS-467, GS-468, GS-471, GS-474, GS-476, GS-477, GS-481, GS-487, GS- } \\
\text { 492, GS-499, GS-503, GS-504, GS-514, GS-518, GS-520, GS-531, GS-537, GS-539, GS-542, GS-543, } \\
\text { GS-554, GS-574, GS-580, GS-581, GS-584, GS-585, GS-590, GS-592, GS-595, GS-596, GS-597, GS-598, } \\
\text { GS-601, GS-602, GS-603, GS-617, GS-628, GS-634, GS-639, GS-662, SKUA-412, AVT-V2, AVT-FG-V5, } \\
\text { AVT-IV1, SKUA-478, SKUA-496, Purple rice, AVT-FG-V10, AVT-FG-V2, AVT-FG-V4, SKUA-404, AVT-FG- } \\
\text { V7, SKUA-500, Egyptian rice, SKUA-415, SKUA-499, SKUA-491, AVT-IV3, Chenab, China-988 }\end{array}$ \\
\hline
\end{tabular}

\section{Figures}




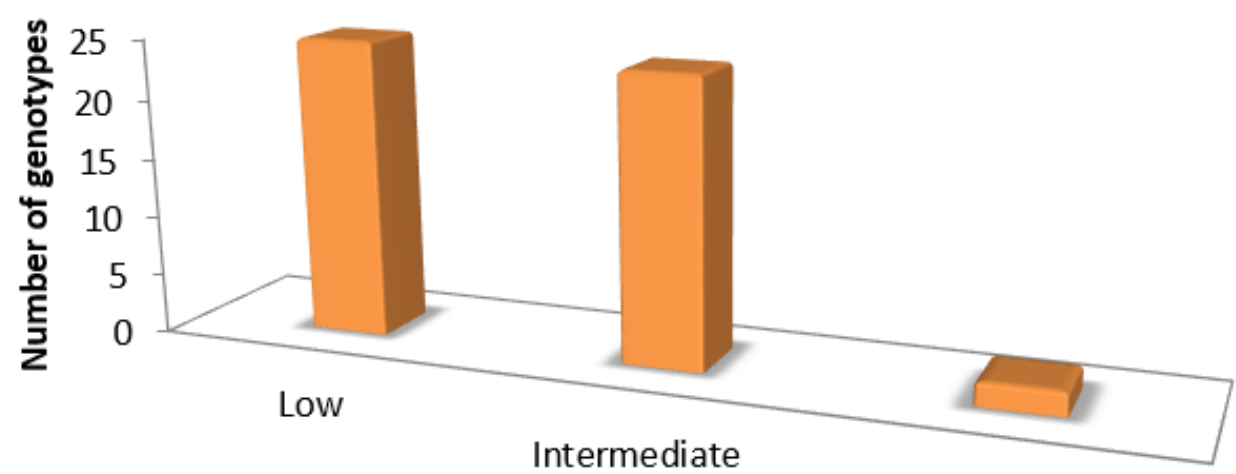

High

Amylose content (\%)

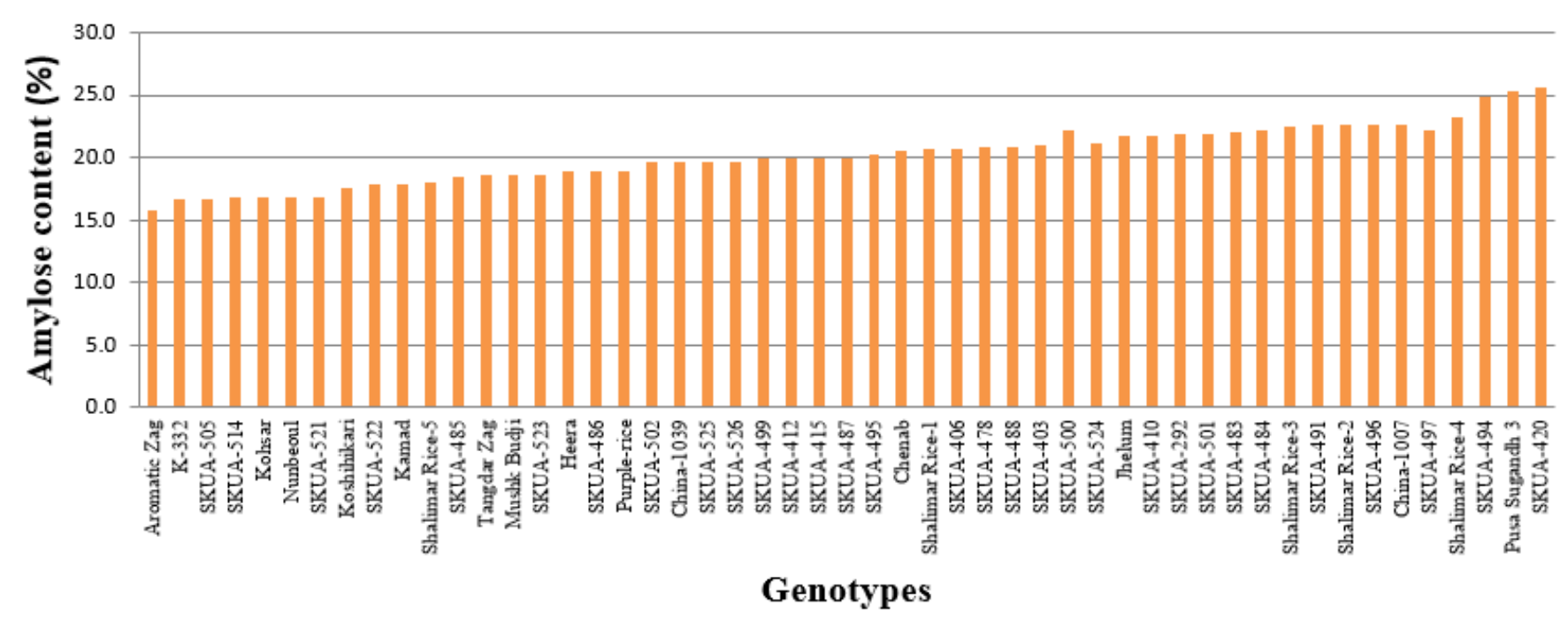

Figure 1

Frequency distribution of Amylose content among rice genotypes

AC: Amylose content where, 9.1-20\% = low amylose content, $20.1-25 \%=$ medium amylose content, $25.1-33 \%$;= high amylose content 


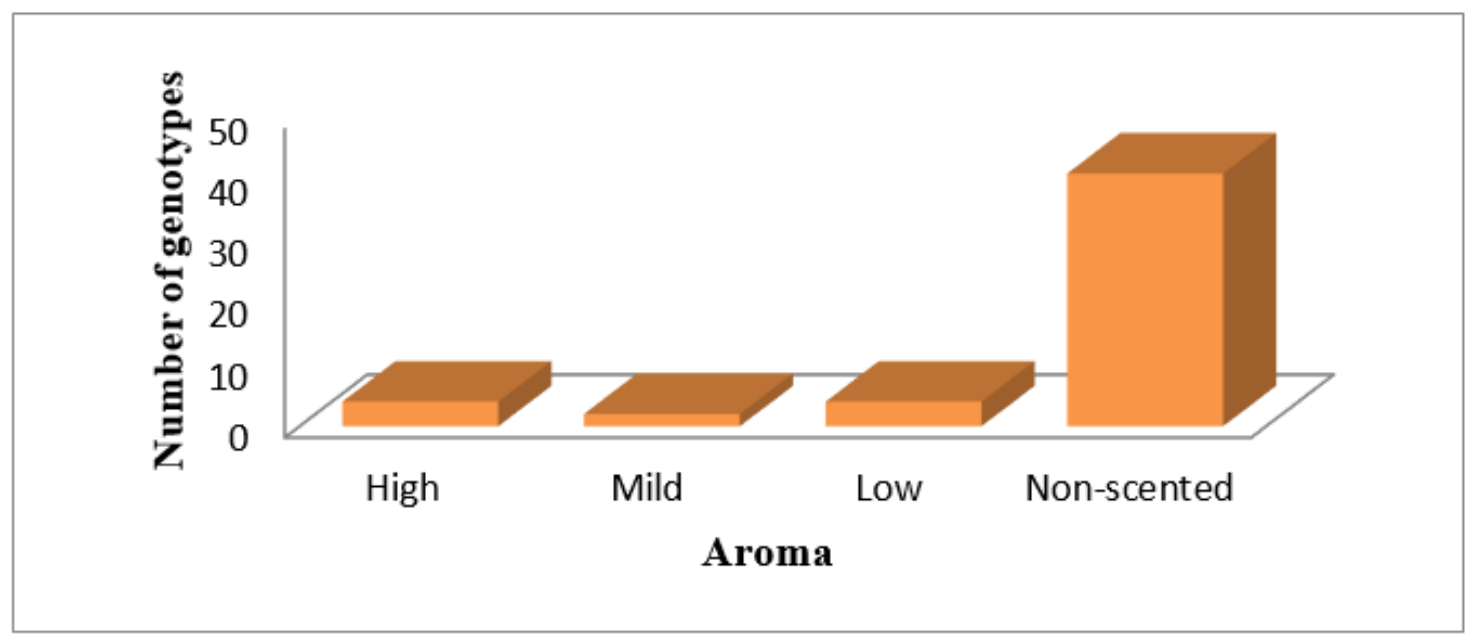

Figure 2

Frequency distribution of aroma among rice genotypes

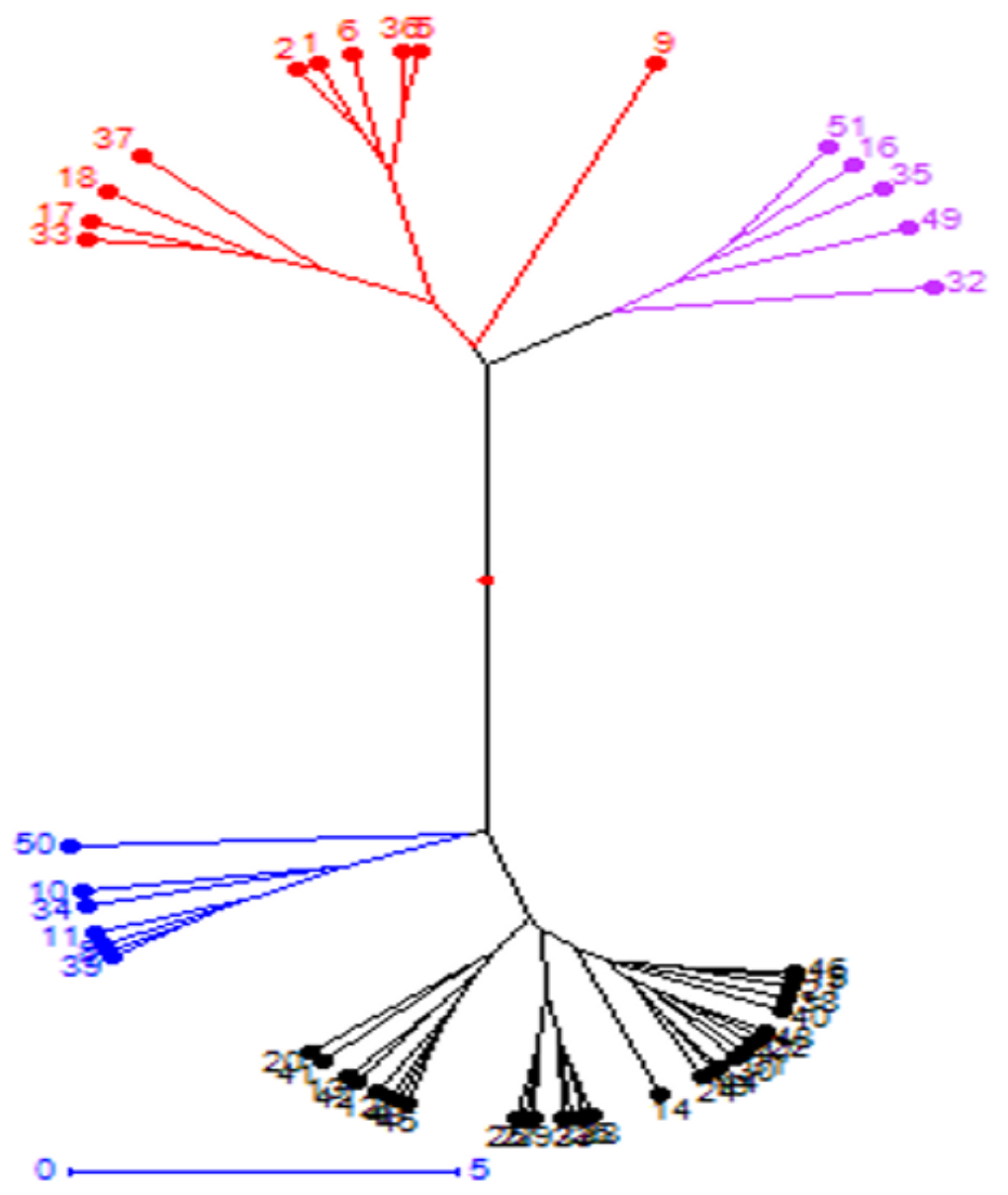

Figure 3 
Dendrogram of 51 rice genotypes generated through DARwin software using unweighted neighbor joining method based on agro-morphological traits

Cluster I: [Kamad, Tangdar Zag, Mushkbudji and Aromatic Zag]; [Shalimar Rice-5, K-332, SKUA-505, Kohsar and SKUA-514]; [SKUA-485]; [Purple rice, SKUA-420, Heera, SKUA-494 and Pusa Sugandh 3]

Cluster II: [Nunbeoul, SKUA-491, Koshihikari, SKUA-495, SKUA-488, SKUA-406 and China-1039]; [Shalimar Rice-2, Shalimar Rice4, SKUA-501, SKUA-412, SKUA-500, Shalimar Rice-1, SKUA-415 and SKUA-487]; [SKUA-478, SKUA-496, SKUA-502, Jhelum, SKUA-410, SKUA-488 and SKUA-499]; [SKUA-524, SKUA-483, Chenab, SKUA-486, SKUA-523, SKUA-526, SKUA-521, SKUA-292, SKUA-522, Shalimar Rice-3, China-1007, SKUA-403, SKUA-403, SKUA-525, SKUA-497].

] designates sub-cluster

\section{Figure 4}

Agarose Gel image depicting SSR marker (RM252) amplification profile of 38 rice genotypes

L; Ladder, 1; SKUA-484, 2; Aromatic Zag, 3; SKUA-487, 4; Nunbeoul, 5; SKUA-499, 6; Koshihikari, 7; SKUA-488, 8; Shalimar Rice-2, 9; SKUA-403, 10; Chenab, 11; SKUA-406, 12; SKUA-500, 13; SR-4, 14;SKUA-483, 15; Shalimar Rice-3, 16; SKUA-410, 17; SKUA412, 18; SKUA-494, 19; Pusa Sughandh 3 20; SKUA-495, 21; SKUA-486, 22; SKUA-491, 23; SKUA-420, 24; Kamad, 25; Heera, 26; SKUA-415, 27; Tangdar Zag, 28; SKUA-478, 29; China-1007, 30; SKUA-522, 31; SKUA-524, 32; SKUA-525, 33; SKUA-526, 34; Shalimar Rice-5, 35; K-332, 36; SKUA-514, 37; SKUA-505 and 38; China-1039.

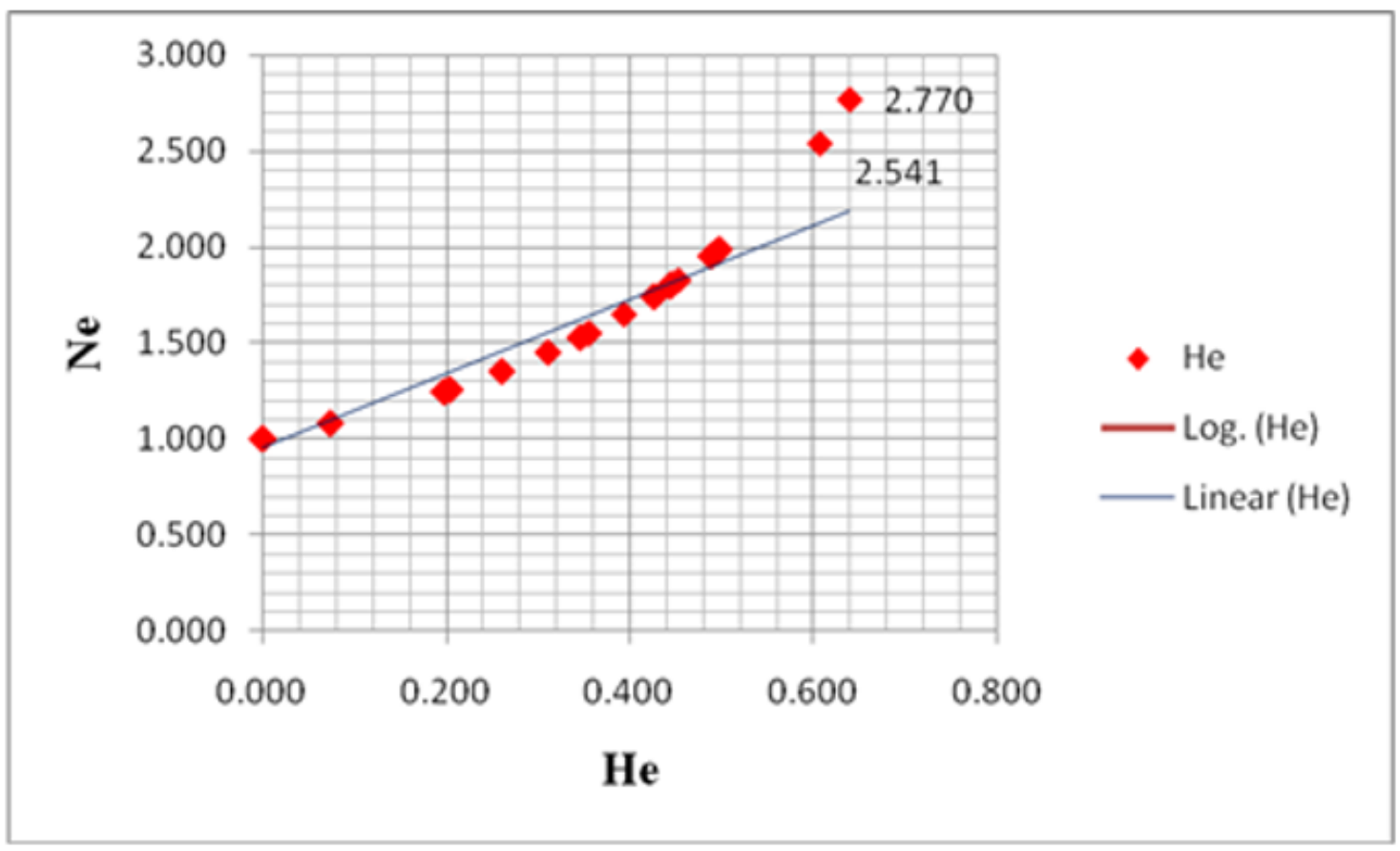

\section{Figure 5}

Number of effective alleles in relation with gene diversity 


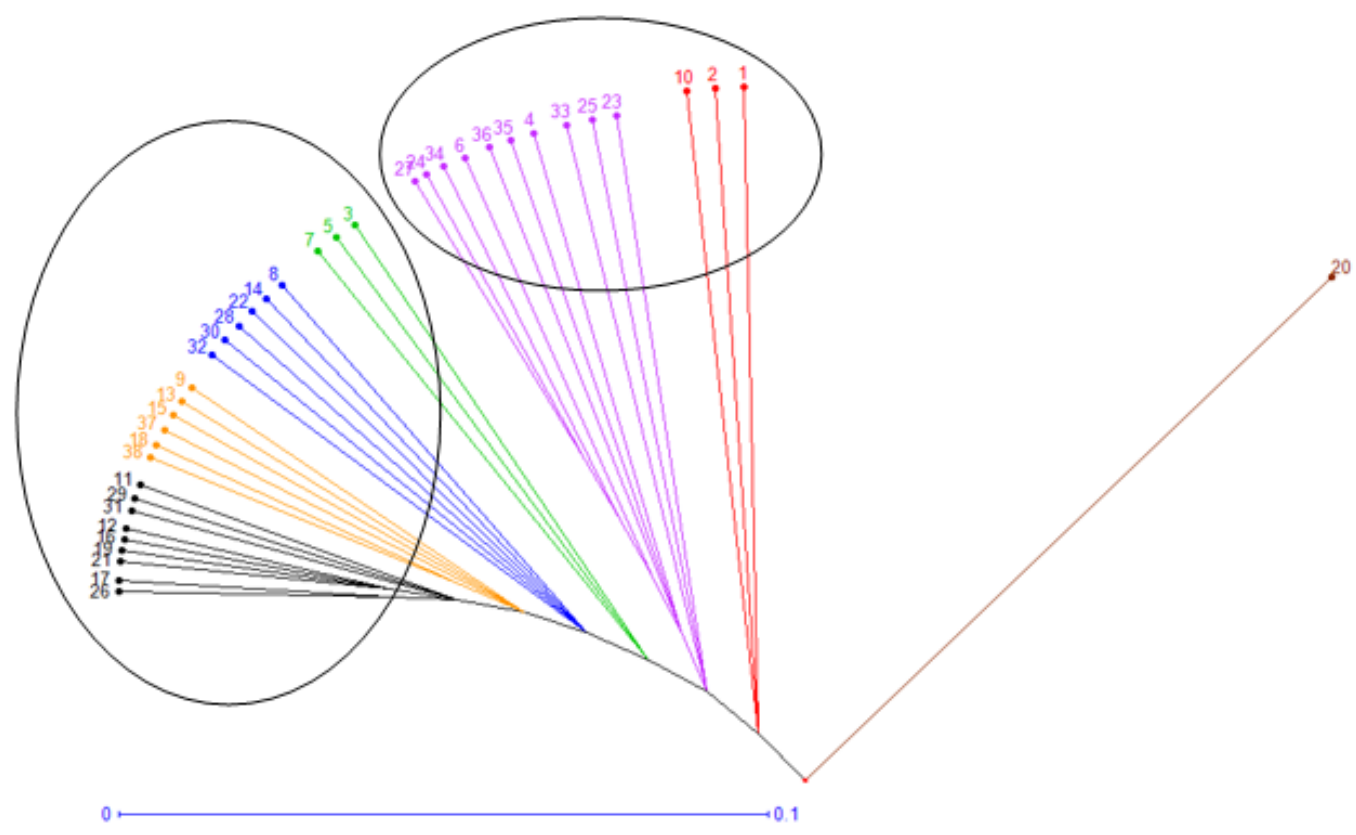

Figure 6

UPGMA based clustering pattern showing genetic relationship among 38 genotypes based on genetic distance matrix using24 SSR markers

Cluster I:[SKUA-415, SKUA-412, SKUA-486, Pusa Sugandh 3, SKUA-410, SKUA-500, SKUA-524, China-1007 and SKUA-406]; [China-1039, SKUA-494, SKUA-505, Shalimar Rice-3, Shalimar Rice-4, SKUA-403, SKUA-525, SKUA-522, SKUA-478, SKUA-491, SKUA-483, Shalimar Rice-2, SKUA-488, SKUA-499 and SKUA-487].

Cluster II: [Tangdar Zag, Kamad, Shalimar Rice-5, Koshihikari, SKUA-514, K-332, Nunbeoul, SKUA-526, Heera and SKUA-420]; [Chenab, Aromatic Zag and SKUA-484]. SKUA-495 did not fall in any clusterand appear as distint one. [] indicates sub-clusters

\section{Supplementary Files}

This is a list of supplementary files associated with this preprint. Click to download.

- supp.tables12.docx 